\title{
mRNA Expression of MMP-28 (Epilysin) in Gingival Tissues of Chronic and Aggressive Periodontitis Patients: A Reverse Transcriptase PCR Study
}

\author{
P. Padmavati, S. Savita, B. M. Shivaprasad, Krishna Kripal, and K. Rithesh \\ Department of Periodontology, Rajarajeswari Dental College and Hospital, Bangalore, Karnataka 560085, India \\ Correspondence should be addressed to B. M. Shivaprasad; drshivaprasad2008@yahoo.co.in
}

Received 15 April 2013; Accepted 8 July 2013

Academic Editor: Gunter Haroske

Copyright (C) 2013 P. Padmavati et al. This is an open access article distributed under the Creative Commons Attribution License, which permits unrestricted use, distribution, and reproduction in any medium, provided the original work is properly cited.

\begin{abstract}
Background and Objectives. Matrix metalloproteinases degrade extracellular membrane and also release bioactive fragments and growth factors, thus influencing fundamental biological and pathological processes. Epilysin (MMP-28) differs from most other MMPs as it is expressed in a number of normal tissues, suggestive of functions in tissue homeostasis. The aim of the present study was to quantitatively evaluate and compare the mRNA expression of epilysin (MMP-28) in gingival tissues of healthy patients and of patients affected by chronic or aggressive periodontitis. Methods. A total of 60 subjects, 20 periodontally healthy subjects, 20 with chronic periodontitis, and 20 with aggressive periodontitis, were included in this study. Periodontal status was evaluated by measuring gingival index, probing depth and clinical attachment level. mRNA expression of MMP-28 was determined by quantitative real-time reverse transcriptase polymerase chain reaction (RT-PCR) in gingival tissue samples collected. Results. Relative quantification of mRNA expression of MMP-28 was highest in healthy tissues (RQ $=0.97)$ when compared to subjects with chronic periodontitis $(\mathrm{RQ}=0.37)$ and aggressive periodontitis $(\mathrm{RQ}=0.23)$, but the difference was not statistically significant. Conclusion. mRNA expression of MMP-28 was highest in healthy tissues when compared to diseased periodontal tissues suggesting that MMP-28 could act as a biomarker for periodontal health.
\end{abstract}

\section{Introduction}

Periodontitis is the result of complex interactions between periodontopathogenic bacteria, the host defence immune system, and environmental factors. The components of the periodontal tissue extracellular matrix, especially collagens, appear to be the main targets of degradation in periodontitis. Among host proteases degrading the extracellular matrix, matrix metalloproteinases (MMPs) seem to be highly related to tissue destruction and remodeling events in periodontal diseases $[1,2]$.

Matrix metalloproteinases (MMPs) comprise a family of 24 structurally related, zinc-dependent endopeptidases capable of degrading most extracellular membrane (ECM) components as well as several cell surface and pericellular proteins [3]. The activity of MMPs influences cell function and response to the microenvironment and plays a central role in various biological processes including development, wound healing, inflammation, angiogenesis, and pathological conditions such as periodontitis, arthritis, tumor cell invasion and metastasis [4].

MMP-28 (epilysin), structurally belonging to the MMP19 subfamily, may represent the newest MMP member and was originally cloned from keratinocyte, testes, and mixed tumour cDNA libraries $[5,6]$. Its expression has been documented in a number of normal tissues, for example, testes, lung, intestine, heart, brain, and skin as well as in a variety of tumour and tumour cell lines.

MMP-28 is expressed in the basal and suprabasal epidermis in intact skin, whilst in injured skin, expression is seen in basal keratinocytes both at and some distance from the wound edge, suggesting that this new MMP is expressed in intact tissues and upregulated in response to injury and may function in both tissue homeostasis and in repair [5]. In contrast, in another study on dermal wound healing epilysin was not detected in migrating keratinocytes at the wound 
edge [7]. Thus epilysin could play a role either in epithelial cell proliferation or in the restructuring of newly formed basement membrane during wound repair.

The involvement of MMP-28 in pathological processes remains obscure. For example, in the inflammatory conditions, it was shown to be upregulated in osteoarthritis by immunohistochemistry (IHC) [8] but downregulated in inflammatory bowel disease or ischemic colitis by real-time PCR [9].

The diagnosis of periodontal disease is traditionally based on clinical parameters and indices that reflect a history of periodontal diseases but cannot predict future disease activity. These conventional clinical approaches are often amended by microbial analysis. In previous studies the best known members of MMP family such as MMP 1, 3, 7, 8, $9,13,25$ and MMP 26 have been widely investigated in gingival tissue and GCF samples of patients with different periodontal diseases and were implicated to be associated with the progression of periodontal diseases [10, 11, 11-14]. To the best of our knowledge gene expression levels of MMP-28 have not been investigated in periodontal diseases. The aim of the present study was to quantitatively analyse and compare the mRNA expression of epilysin (MMP-28) in gingival tissues of various groups such as subjects with healthy periodontium, chronic periodontitis, and aggressive periodontitis patients.

\section{Materials and Methods}

2.1. Patient Selection. The study population consisted of 60 systemically healthy subjects with an age range of $14-58$ years and included 27 women and 33 men. All participants were selected randomly from the outpatient section, Department of Periodontology, Rajarajeswari Dental College and Hospital, Bangalore. The study was conducted in accordance with the Declaration of Helsinki of 1975, as revised in 2000, and was approved by institutional ethics and research committee, Rajarajeswari Dental College and Hospital, Bangalore. The purpose of the study was explained to each subject and a written informed consent was obtained from every participant before inclusion in the study.

The selection of the patients was made according to the clinical and radiographic criteria by the 1999 classification of periodontal disease and conditions [15].

2.1.1. Healthy Group (Healthy). The healthy group included 12 males and 8 females in age group of of $15-34$ years (mean: $24.60 \pm 5.32$ years) who exhibited no clinical inflammation with a probing depth $(\mathrm{PD})<3 \mathrm{~mm}$, no clinical attachment loss (CAL), or radiographic evidence of alveolar bone loss.

2.1.2. Chronic Periodontitis Group (CP). The CP group consisted of 8 males and 12 females ranging in age from 25 to 58 years (mean: $37.85 \pm 10.90$ years). They had moderate to severe bone loss, probing depth $\geq 5 \mathrm{~mm}$, clinical attachment loss $\geq 3 \mathrm{~mm}$, but with no evidence of rapid progression of disease.
2.1.3. Aggressive Periodontitis Group (AgP). The group included 13 males and 7 females ranging in age from 17 to 42 years (mean: $29.25 \pm 6.78$ years). These patients demonstrated amount of microbial deposits inconsistent with disease severity, probing depth $\geq 5 \mathrm{~mm}$, presence of interproximal attachment loss $\geq 3 \mathrm{~mm}$, and radiographic evidence of alveolar bone loss.

The exclusion criteria were as follows: presence of known systemic disease or condition that could affect the periodontal tissues, smokers and alcoholic patients, pregnant and lactating mothers, and patients on immunosuppressive agents or antibiotics taken within the last 6 months and who had undergone periodontal treatment within a period of one year.

2.2. Clinical Examination. The screening of patients was done using mouth mirror and graduated Williams periodontal probe. Gingival status was assessed by using gingival index of Löe [16] and periodontal status assessed by measuring the pocket probing depth and loss of attachment. All parameters were assessed and samples were taken by one calibrated examiner (PP).

2.3. Tissue Sampling. Gingival tissue samples were harvested during periodontal surgery and extraction of the periodontally hopeless tooth for the periodontitis patients and during the premolar extraction or third molar extraction for the healthy controls. While obtaining gingival tissue from periodontitis patients, it was made sure that it should include pocket epithelium and granulation tissue. The collected sample was immediately stored at $-80^{\circ} \mathrm{C}$ until analysis. Sample storage and all the PCR procedures were carried out in the research department of Rajarajeswari Dental College and Hospital Bangalore.

\subsection{RT-PCR Procedure}

2.4.1. Isolation of Total RNA. Gingival tissue was homogenized thoroughly using a tissue homogenizer, and then total cellular RNA was isolated with a total RNA isolation kit according to the manufacturer's instructions (mirVANA miRNA isolation kit, Ambion by Life Technologies, India). The total RNA obtained was treated with RNase-free DNase to remove any contaminating DNA. The eluate (which contains the RNA) was collected and stored at $-20^{\circ} \mathrm{C}$ or below.

2.4.2. Reverse Transcription and cDNA Synthesis. Total RNA $(3 \mu \mathrm{L})$ was reverse transcribed (High capacity cDNA Reverse Transcriptase enzyme, Applied Biosystems, India) in duplicate by incubating samples for 120 minutes at $37^{\circ} \mathrm{C}$ in $20 \mathrm{~mL}$ reaction mixture containing $2.0 \mu \mathrm{L} 10 \mathrm{x}$ RT Buffer, $0.8 \mu \mathrm{L}$ 25x dNTP Mix, $2.0 \mu \mathrm{L}$ 10x RT Random Primers, and $11.2 \mu \mathrm{L}$ nuclease-free water.

2.4.3. Quantitative Real-Time RT-PCR. Custom TaqMan mRNA expression assay for MMP-28 was used in this study (Custom TaqMan gene expression assays by Applied Biosystems, India). In brief, a reaction solution composed 
TABLE 1: Distribution of patients in three groups (healthy, chronic periodontitis, and aggressive periodontitis) by age groups.

\begin{tabular}{|c|c|c|c|c|c|c|c|}
\hline Age groups & Healthy & $\%$ & $\begin{array}{c}\text { Chronic } \\
\text { periodontitis }\end{array}$ & $\%$ & $\begin{array}{c}\text { Aggressive } \\
\text { periodontitis }\end{array}$ & $\%$ & Total \\
\hline $15-24$ yrs & 9 & 45.0 & 0 & 0.0 & 6 & 30.0 & 18 \\
\hline $25-34$ yrs & 11 & 55.0 & 6 & 30.0 & 9 & 45.0 & 23 \\
\hline $35+\mathrm{yrs}$ & 0 & 0.0 & 14 & 70.0 & 5 & 25.0 & 19 \\
\hline Total & 20 & 100.0 & 20 & 100.0 & 20 & 100.0 & 60 \\
\hline Mean age & \multicolumn{2}{|c|}{24.60} & \multicolumn{2}{|c|}{37.85} & \multicolumn{2}{|c|}{29.25} & 30.57 \\
\hline SD age & \multicolumn{2}{|c|}{5.32} & \multicolumn{2}{|c|}{10.90} & \multicolumn{2}{|c|}{6.78} & 9.63 \\
\hline
\end{tabular}

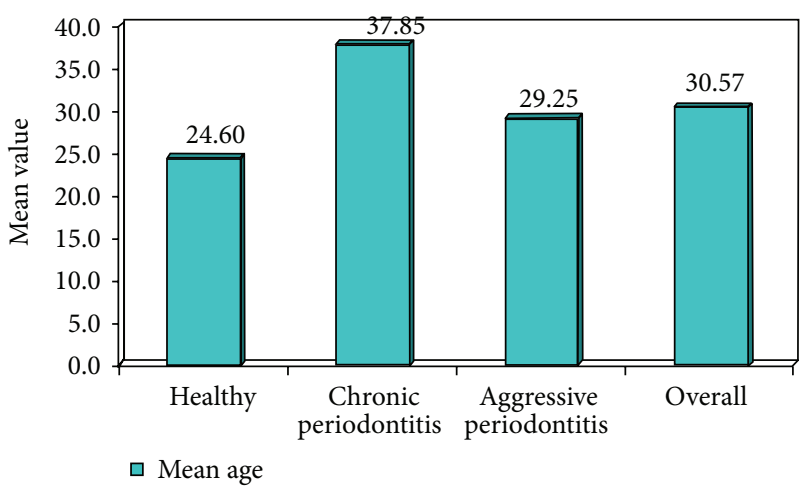

FIGURE 1: Comparison of mean and SD age in three groups.

of TaqMan Universal PCR Master Mix $(10 \mu \mathrm{L})$, forward and reverse primers, specific taqMan probe (final concentration $1 \mu \mathrm{L})$, and cDNA mixture $(1 \mu \mathrm{L})$ was mixed to a total volume of $20 \mu \mathrm{L}$. The conditions for real-time RT-PCR were as follows: preheating at $50^{\circ} \mathrm{C}$ for 2 minutes and at $95^{\circ} \mathrm{C}$ for 10 minutes, followed by 40 cycles of shuttle heating at $95^{\circ} \mathrm{C}$ for 15 seconds and at $60^{\circ} \mathrm{C}$ for 1 minute. 18s RNA was used as endogenous control (TaqMan predeveloped assay reagents, Applied Biosystems, India). Relative quantification (RQ) based on the Ct (the number of PCR cycles necessary to obtain the threshold signal of fluorescence) values was analysed using Applied Biosystems Software. The comparative threshold cycle or Ct method was used to quantify the amplified transcripts.

2.5. Statistical Analysis. Kruskal Wallis ANOVA was used for comparison of three groups (healthy, chronic periodontitis, and aggressive periodontitis) with respect to gingival index scores. Pairwise comparison of three groups with respect to PPD, CAL, and mRNA expression of MMP-28 were studied using Tukey's multiple post hoc procedures. One-way ANOVA was performed to compare among the three groups the relative quantification of mRNA expression of MMP28. A commercially available statistical software program was used for the statistical analysis. The level of statistical significance was set at 5\% $(P<0.05)$.

\section{Results}

The present cross-sectional clinical study was undertaken to quantitatively analyse the mRNA expression of epilysin
TABLE 2: Mean values of all measured clinical parameters.

\begin{tabular}{lccc}
\hline & $\begin{array}{c}\text { Healthy } \\
\text { group }\end{array}$ & $\begin{array}{c}\text { Chronic } \\
\text { periodontitis } \\
\text { group }\end{array}$ & $\begin{array}{c}\text { Aggressive } \\
\text { periodontitis } \\
\text { group }\end{array}$ \\
\hline Gingival index & $0.2 \pm 0.08$ & $1.85 \pm 0.38$ & $1.49 \pm 0.52$ \\
$\begin{array}{l}\text { Probing pocket depth } \\
\text { Clinical attachment }\end{array}$ & $1.94 \pm 0.4$ & $7.1 \pm 0.7$ & $7.4 \pm 0.6$ \\
level & 0.00 & $7.2 \pm 0.7$ & $7.1 \pm 0.8$ \\
\hline
\end{tabular}

TABLE 3: Comparison of three groups (healthy, chronic periodontitis, and aggressive periodontitis) with respect to relative quantification of mRNA expression of MMP-28 scores by one-way ANOVA.

\begin{tabular}{lccccc}
\hline SV & DF & $\begin{array}{c}\text { Sum of } \\
\text { squares }\end{array}$ & $\begin{array}{c}\text { Mean sum } \\
\text { of squares }\end{array}$ & $F$ value & $P$ value \\
\hline Between groups & 2 & 6.1213 & 3.0606 & 1.9777 & 0.1478 \\
Within groups & 57 & 88.2121 & 1.5476 & & \\
\hline Total & 59 & 94.3334 & & & \\
\hline
\end{tabular}

(MMP-28) in gingival tissues of various groups such as subjects with healthy periodontium, chronic periodontitis, and aggressive periodontitis patients. The mean age of subjects in all three groups is mentioned in Table 1 and Figure 1.

Gingival index scores analyzed by Kruskal Wallis ANOVA for healthy controls, CP group, and AgP group were $0.2 \pm 0.08,1.85 \pm 0.38$, and $1.49 \pm 0.52$, respectively. Gingival index scores compared for 3 groups were statistically significant. The mean PD score in CP group and AgP group was significantly higher than the healthy group. Mean probing depth of healthy controls was $1.94 \pm 0.41$, in the chronic periodontitis group was $7.1 \pm 0.78$, and in the aggressive periodontitis group was $7.4 \pm 063$. Comparison among three groups was statistically significant. The Mean clinical attachment level for CP group and AgP group was $7.25 \pm 0.77,7.1 \pm 0.80$, respectively and significantly higher than healthy group (Table 2).

Analysis of variance (ANOVA) for relative quantification of mRNA expression of MMP-28 among the three groups, healthy, chronic and aggressive periodontitis was not statistically significant $(P=0.15)$ (Figure 2 , Table 3 ).

Pair wise comparison of the three groups using Tukey's multiple post hoc procedure (Table 4) showed the mean relative quantification (RQ) of MMP-28 gene expression to be 
TABLE 4: Pairwise comparison of three groups (healthy, chronic periodontitis, and aggressive periodontitis) with respect to relative quantification of mRNA expression of MMP-28 scores by Tukey's multiple post hoc procedures.

\begin{tabular}{lccc}
\hline Groups & Healthy & $\begin{array}{c}\text { Chronic } \\
\text { periodontitis }\end{array}$ & $\begin{array}{c}\text { Aggressive } \\
\text { periodontitis }\end{array}$ \\
\hline Mean & 0.9700 & 0.3780 & 0.2310 \\
Std. Dev. & 2.0861 & 0.4466 & 0.3021 \\
Healthy & - & & \\
Chronic periodontitis & $P=0.2964$ & - & \\
Aggressive periodontitis & $P=0.1543$ & $P=0.9261$ & - \\
\hline
\end{tabular}

TABLE 5: Correlation coefficient between relative quantification of mRNA expression of MMP-28 scores with GI, PPD and CAL scores by Karl Pearson's correlation coefficient method in healthy group.

\begin{tabular}{lccc}
\hline & \multicolumn{3}{c}{$\begin{array}{c}\text { Correlation coefficient between relative } \\
\text { Vuantification of mRNA expression of MMP-28 } \\
\text { scores with }\end{array}$} \\
& $\begin{array}{c}\text { Correlation coefficient } \\
(r \text { value })\end{array}$ & $t$ value & $P$ value \\
\hline GI & 0.0437 & 0.1855 & 0.8549 \\
PPD & -0.2136 & -0.9274 & 0.3660 \\
CAL & - & - & - \\
\hline
\end{tabular}

TABLE 6: Correlation coefficient between relative quantification of mRNA expression of MMP-28 scores with GI, PPD and CAL scores by Karl Pearson's correlation coefficient method in chronic periodontitis group.

\begin{tabular}{lccc}
\hline Variables & \multicolumn{2}{c}{$\begin{array}{c}\text { Correlation coefficient between relative } \\
\text { quantification of mRNA expression of MMP-28 } \\
\text { scores with }\end{array}$} \\
& $\begin{array}{c}\text { Correlation coefficient } \\
(r \text { value })\end{array}$ & $t$ value & $P$ value \\
\hline GI & -0.1753 & -0.7553 & 0.4598 \\
PPD & 0.4240 & 1.9861 & 0.0625 \\
CAL & 0.2409 & 1.0531 & 0.3062 \\
\hline
\end{tabular}

TABLE 7: Correlation coefficient between relative quantification of mRNA expression of MMP-28 scores with GI, PPD and CAL scores by Karl Pearson's correlation coefficient method in aggressive periodontitis group.

\begin{tabular}{lccc}
\hline Variables & \multicolumn{2}{c}{$\begin{array}{c}\text { Correlation coefficient between Relative } \\
\text { Quantification of mRNA expression of MMP-28 } \\
\text { scores with }\end{array}$} \\
& $\begin{array}{c}\text { Correlation coefficient } \\
(r \text { value })\end{array}$ & $t$ value & $P$ value \\
\hline GI & 0.1524 & 0.6542 & 0.5213 \\
PPD & 0.2107 & 0.9145 & 0.3725 \\
CAL & 0.2170 & 0.9430 & 0.3582 \\
\hline
\end{tabular}

highest in gingival tissues of subjects with healthy periodontium $(\mathrm{RQ}=0.97 \pm 2.08)$. Least MMP-28 gene expression was found in aggressive periodontitis $(\mathrm{RQ}=0.23 \pm 0.30)$, whereas

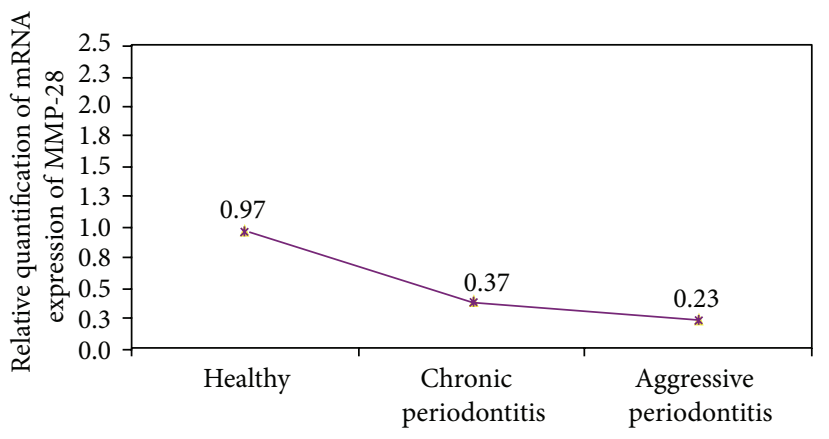

FIGURE 2: Comparison of three groups (healthy, chronic periodontitis, and aggressive periodontitis) with respect to relative quantification of mRNA expression of MMP-28 scores.

that of chronic periodontitis was present between the above two values $(\mathrm{RQ}=0.37 \pm 0.44)$.

However, no statistically significant differences in the gene expression levels of MMP-28 were found between healthy and chronic periodontitis, healthy and aggressive periodontitis, and between chronic and aggressive periodontitis patients (Table 4 ).

Correlation coefficient $r$ value showed that MMP-28 was positively correlated with gingival index $(r=0.04)$ and negatively correlated with probing pocket depth in healthy subjects $(r=-0.21)$ (Table 5$)$. In chronic periodontitis group, correlation coefficient $r$ value showed MMP-28 to be negatively correlated with gingival index $(r=-0.17)$ and positively correlated with probing pocket depth $(r=$ $0.42)$ and clinical attachment level $(r=0.24)$ (Table 6). In aggressive periodontitis group, MMP-28 was found to be positively correlated with gingival index $(r=0.15)$, probing pocket depth $(r=0.21)$, and clinical attachment level $(r=$ 0.21) (Table 7).

\section{Discussion}

As a result of the interaction between the bacterial infection and immune (host) response, irreversible destruction of periodontal connective tissue and alveolar bone occurs. This destruction is mediated to a significant extent by the host cells derived MMPs.

In the present cross-sectional clinical study, a total number of 60 subjects, fulfilling the inclusion and exclusion criteria were selected. The study assessed the mRNA expression of MMP-28 in gingival samples from periodontitis-affected patients and from healthy patients using real-time RT-PCR. Gingival index, mean probing pocket depth (PPD), and clinical attachment level (CAL) scores in AgP and CP groups were significantly higher than the healthy group $(P<0.001)$. These results are in agreement with findings of previous studies by Alpagot et al. [17] and Yakob et al. [18].

The mean relative quantification (RQ) of MMP-28 gene expression was found to be highest in gingival tissues of subjects with healthy periodontium $(\mathrm{RQ}=0.97 \pm 2.08)$. Although MMP-28 gene expression was higher in healthy samples, the expression levels between healthy and chronic 
periodontitis, healthy and aggressive periodontitis, chronic and aggressive periodontitis was not statistically significant. MMP-28 gene expression in aggressive periodontitis group and chronic periodontitis group were $R Q=0.23 \pm 0.30$ and $\mathrm{RQ}=0.37 \pm 0.44$, respectively.

The higher gene expression of MMP-28 found in healthy subjects could be partly attributed to its association with normal tissue homeostasis and turnover. A previous study demonstrated increased expression of epilysin in normal intact tissues. It was found that epilysin mRNA was highly expressed in testis and at lower levels in lungs, heart, colon, intestine, and brain. Immunohistochemical staining showed expression of epilysin protein in the basal and suprabasal epidermis of intact skin. The staining intensity was strongest in basal keratinocytes and progressively weaker in suprabasal cells [19].

This expression pattern distinguishes epilysin from most other MMP family members, as most MMPs are expressed only under exceptional conditions such as those related to injury, inflammation, or disease. Inflammatory mediators regulate many MMPs (e.g., MMP-1, MMP-3, MMP-9, MMP$13)$, as shown in the literature, but not MMP-28 [10, 11, 11, $13,18]$. Gene expression levels of MMP-28 were investigated in traumatic and degenerative human intervertebral disc degeneration tissue by real-time RT-PCR and found that stimulation with inflammatory mediators like lipopolysaccharide (LPS), IL-1 $\beta$, TNF- $\alpha$, or trichostatin-A did not alter MMP-28 gene expression at any investigated time point or any concentration. This data indicates that compared to other MMPs, human MMP-28 expression seems to be unresponsive to inflammatory stimuli and not regulated by inflammatory mechanisms [20].

Another study detected epilysin protein in the apical regions of the villi in normal ileum and colon. Unlike other MMPs (MMP-19, MMP-26), MMP-28 expression remained unaffected by inflammation suggesting MMP-28 is not associated with inflammatory and destructive changes seen in inflammatory bowel disease [9].

In contrast, however, when primary keratinocytes were stimulated with tumor necrosis factor $\alpha$, upregulation of epilysin mRNA was evident within $24 \pm 48$ hrs as measured by quantitative reverse transcription polymerase chain reaction [7]. The expression of epilysin, in addition to other MMPs, has been detected in mesenchymal stem cells, where its expression was upregulated during chondrogenesis [21].

Many of the secreted MMPs, including MMPs 1, 3, 9, 10,11 , and 13, are not expressed in normal, healthy resting tissues, and with some exceptions, their production and activity are maintained at nearly undetectable levels [12, 13]. However, matrilysin (MMP-7) was shown to be expressed by the epithelium of intact mucosal tissues [22] and reported to function in innate immunity, a homeostatic function, by activating prodefensin peptides [23].

To the best of our knowledge this is the first study demonstrating the quantitative analysis of mRNA expression of MMP-28 in healthy and periodontitis affected gingival tissues using reverse transcriptase real-time PCR. Considering the higher gene expression of MMP-28 in healthy tissues compared to diseased tissues points out a novel role of MMP28 and it could act as a biomarker for periodontal health. However, future studies conducted on larger sample size involving different perspective of MMP-28 might lead to the exploration of therapeutic potential of MMP-28 in treating periodontal diseases.

\section{References}

[1] J. J. Reynolds and M. C. Meikle, "Mechanisms of connective tissue matrix destruction in periodontitis," Periodontology 2000, vol. 1997, no. 14, pp. 144-157, 1997.

[2] T. Sorsa, L. Tjäderhane, Y. T. Konttinen et al., "Matrix metalloproteinases: contribution to pathogenesis, diagnosis and treatment of periodontal inflammation," Annals of Medicine, vol. 38, no. 5, pp. 306-321, 2006.

[3] A. Miyoshi, Y. Kitajima, K. Sumi et al., "Snail and SIP1 increase cancer invasion by upregulating MMP family in hepatocellular carcinoma cells," British Journal of Cancer, vol. 90, no. 6, pp. 1265-1273, 2004.

[4] T. Sorsa, L. Tjäderhane, and T. Salo, "Matrix metalloproteinases (MMPs) in oral diseases," Oral Diseases, vol. 10, no. 6, pp. 311318, 2004.

[5] J. Lohi, C. L. Wilson, J. D. Roby, and W. C. Parks, "Epilysin, a novel human matrix metalloproteinase (MMP-28) expressed in testis and keratinocytes and in response to injury," Journal of Biological Chemistry, vol. 276, no. 13, pp. 10134-10144, 2001.

[6] G. N. Marchenko and A. Y. Strongin, "MMP-28, a new human matrix metalloproteinase with an unusual cysteineswitch sequence is widely expressed in tumors," Gene, vol. 265, no. 1-2, pp. 87-93, 2001.

[7] U. Saarialho-Kere, E. Kerkelä, T. Jahkola, S. Suomela, J. KeskiOja, and J. Lohi, "Epilysin (MMP-28) expression is associated with cell proliferation during epithelial repair," Journal of Investigative Dermatology, vol. 119, no. 1, pp. 14-21, 2002.

[8] L. Kevorkian, D. A. Young, C. Darrah et al., "Expression profiling of metalloproteinases and their inhibitors in cartilage," Arthritis and Rheumatism, vol. 50, no. 1, pp. 131-141, 2004.

[9] V.-O. Bister, M. T. Salmela, M.-L. Karjalainen-Lendsberg et al., "Differential expression of three matrix metalloproteinases, MMP-19, MMP-26, and MMP-28, in normal and inflamed intestine and colon cancer," Digestive Diseases and Sciences, vol. 49, no. 4, pp. 653-661, 2004.

[10] T. Nomura, T. Takahashi, and K. Hara, "Expression of TIMP1, TIMP-2 and collagenase mRNA in periodontitis-affected human gingival tissue," Journal of Periodontal Research, vol. 28, no. 5, pp. 354-362, 1993.

[11] T. Aiba, N. Akeno, T. Kawane, H. Okamoto, and N. Horiuchi, "Matrix metalloproteinases-1 and -8 and TIMP-1 mRNA levels in normal and diseased human gingivae," European Journal of Oral Sciences, vol. 104, no. 5-6, pp. 562-569, 1996.

[12] T. Kubota, T. Nomura, T. Takahashi, and K. Hara, "Expression of mRNA for matrix metalloproteinases and tissue inhibitors of metalloproteinases in periodontitis-affected human gingival tissue," Archives of Oral Biology, vol. 41, no. 3, pp. 253-262, 1996.

[13] M. Dahan, B. Nawrocki, R. Elkaïm et al., "Expression of matrix metalloproteinases in healthy and diseased human gingiva," Journal of Clinical Periodontology, vol. 28, no. 2, pp. 128-136, 2001.

[14] G. Emingil, H. Kuula, T. Sorsa, and G. Atilla, "Gingival crevicular fluid matrix metalloproteinase-25 and -26 levels in 
periodontal disease," Journal of Periodontology, vol. 77, no. 4, pp. 664-671, 2006.

[15] G. C. Armitage, "Development of a classification system for periodontal diseases and conditions," Annals of Periodontology, vol. 4, no. 1, pp. 1-6, 1999.

[16] H. Löe, "The gingival index, the plaque index and the retention index systems," Journal of Periodontology, vol. 38, no. 6, supplement, pp. 610-616, 1967.

[17] T. Alpagot, C. Bell, W. Lundergan, D. W. Chambers, and R. Rudin, "Longitudinal evaluation of GCF MMP-3 and TIMP1 levels as prognostic factors for progression of periodontitis," Journal of Clinical Periodontology, vol. 28, no. 4, pp. 353-359, 2001.

[18] M. Yakob, K. Kari, T. Tervahartiala et al., "Associations of periodontal microorganisms with salivary proteins and MMP-8 in gingival crevicular fluid," Journal of Clinical Periodontology, vol. 39, no. 3, pp. 256-263, 2012.

[19] S. A. Illman, J. Lohi, and J. Keski-Oja, "Epilysin (MMP-28)structure, expression and potential functions," Experimental Dermatology, vol. 17, no. 11, pp. 897-907, 2008.

[20] M. Klawitter, L. Quero, A. Bertolo et al., "Human MMP28 expression is unresponsive to inflammatory stimuli and does not correlate to the grade of intervertebral disc degeneration," Journal of Negative Results in BioMedicine, vol. 10, no. 1, article 9, 2011.

[21] F. Djouad, B. Delorme, M. Maurice et al., "Microenvironmental changes during differentiation of mesenchymal stem cells towards chondrocytes," Arthritis Research and Therapy, vol. 9, article R33, 2007.

[22] U. K. Saarialho-Kere, E. C. Crouch, and W. C. Parks, "Matrix metalloproteinase matrilysin is constitutively expressed in adult human exocrine epithelium," Journal of Investigative Dermatology, vol. 105, no. 2, pp. 190-196, 1995.

[23] Y. S. López-Boado, C. L. Wilson, L. V. Hooper, J. I. Gordon, S. J. Hultgren, and W. C. Parks, "Bacterial exposure induces and activates matrilysin in mucosal epithelial cells," Journal of Cell Biology, vol. 148, no. 6, pp. 1305-1315, 2000. 


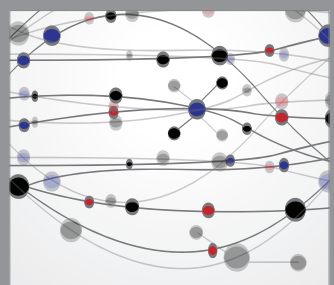

The Scientific World Journal
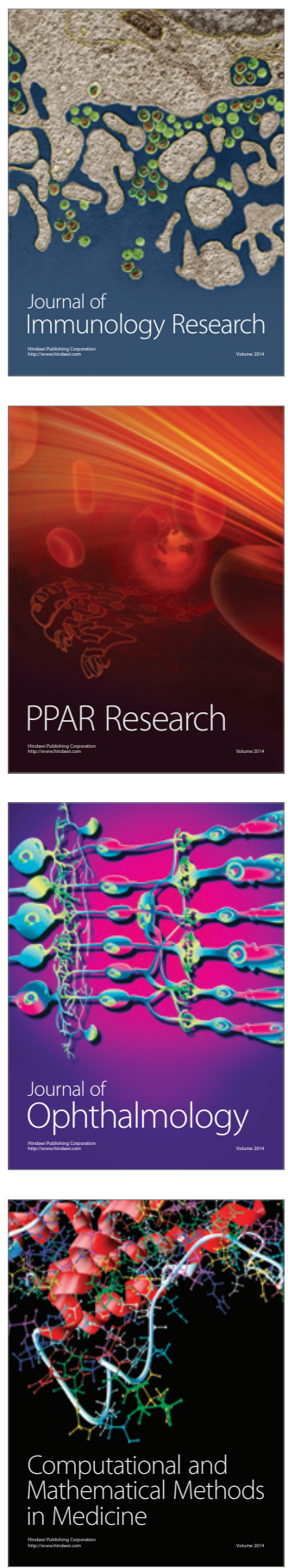

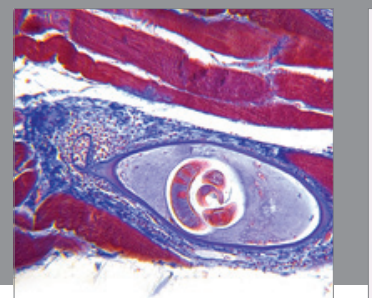

Gastroenterology

Research and Practice
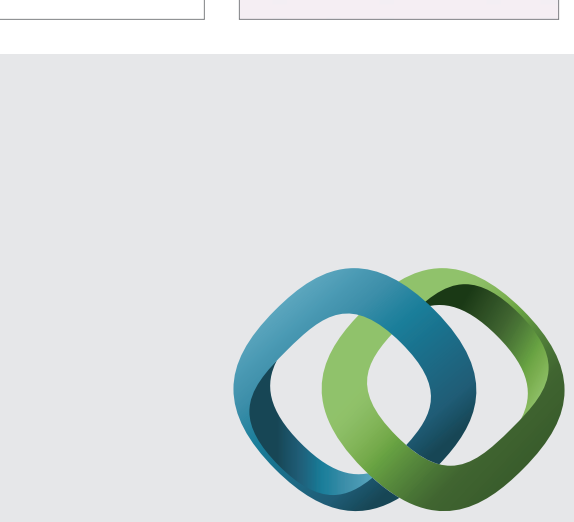

\section{Hindawi}

Submit your manuscripts at

http://www.hindawi.com
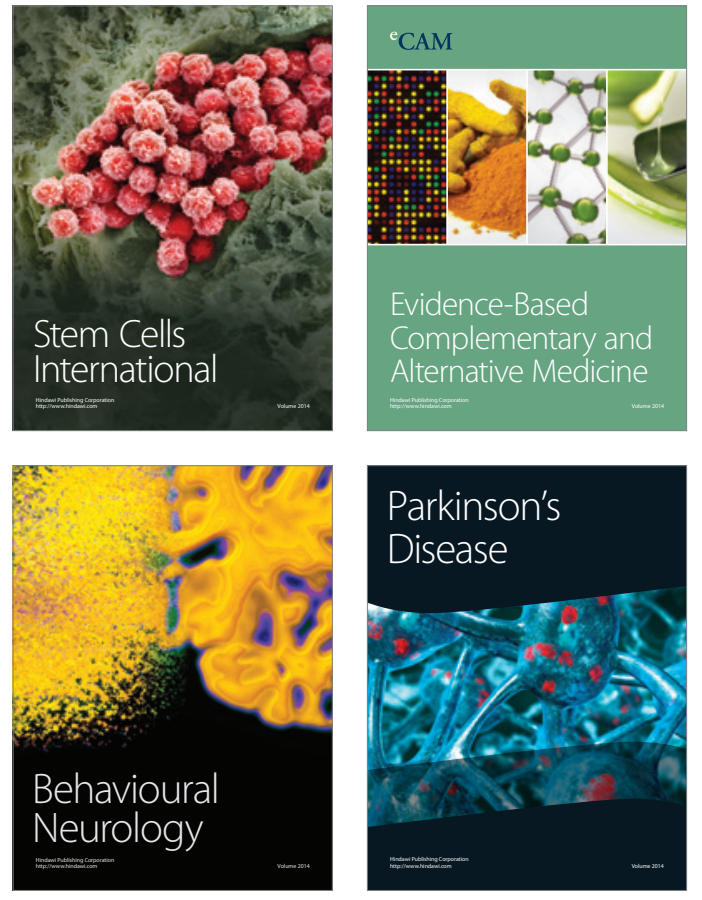
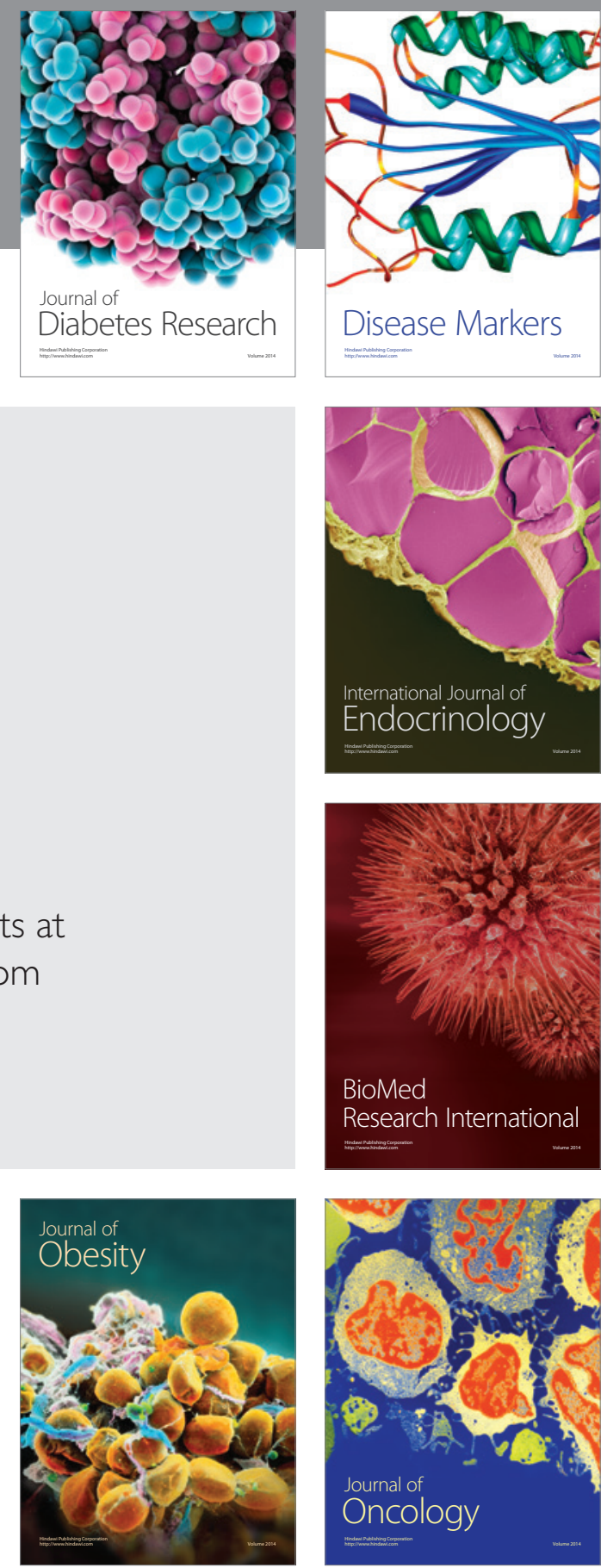

Disease Markers
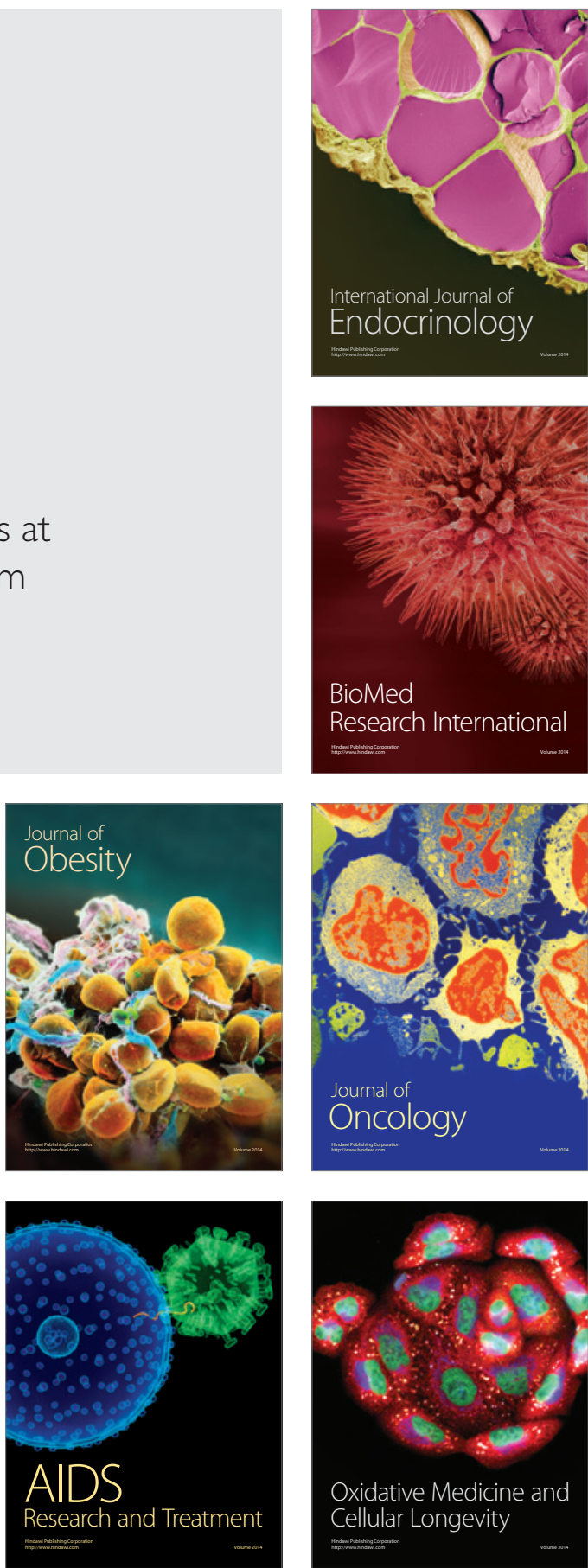